\title{
Сорбционные материалы для твердофазной экстракции вязкостных присадок на основе полиалкилметакрилата из смазочных материалов
}

\author{
(C) 2021 Иванова Ю.А., Темердашев 3.А., Киселева Н.В., Махоткина Д.А. \\ Кубанский государственный университет, Краснодар
}

Поступила в редакцию 1.04.2021 г.

DOI: $10.17308 /$ sorpchrom.2021.21/3463

Работа посвящена изучению сорбционных материалов для твердофазного извлечения вязкостных присадок на основе полиалкилметакрилата из смазочного материала и хроматографическому определению выделенных присадок. Объектами исследования были индивидуальные товарные функциональные присадки на основе полиалкилметакрилата «Максойл В», полиметилметакрилат «Д» (ПМАД). В качестве сорбционных материалов использовали концентрирующие патроны на немодифицированном силикагеле «Диапак Силикагель» и гидроксилированный силикагель (зернение 5-50 мкм). Концентрацию функциональных присадок определяли методом гель-проникающей хроматографии (ГПХ). ГХ-МС идентификацию полимерной присадки в составе элюатов проводили с использованием библиотеки масс-спектров NIST 07. Для каждого сорбента построены динамические кривые сорбции, рассчитаны сорбционные характеристики по отношению к исследуемым вязкостным присадкам («объем до проскока», равновесный объем, объем удерживания и др.). «Объемы до проскока» на обоих сорбентах определили для исследуемых присадок в растворителях с различной полярностью. На сорбенте «Диапак Силикагель» «объемы до проскока» составили для присадок «Максойл В» и ПМАД: в смеси гексан:трихлорметан (7:3 по объему) 0.3 и $0.5 \mathrm{~cm}^{3}$, гексане 0.6 и $0.8 \mathrm{~cm}^{3}$ соответственно. При твердофазном извлечении гидроксилированным силикагелем товарных вязкостных присадок «Максойл В» и ПМАД «объемы до проскока» составили: в смеси гексан:трихлорметан (7:3 по объему) 1.95 и 1.50 см$^{3}$, гексане - 3.40 и $3.01 \mathrm{~cm}^{3}$ соответственно. Степень извлечения товарных вязкостных присадок «Максойл В» и ПМАД гидроксилированным силикагелем оптимальным объемом элюента (ацетоном) $1.5 \mathrm{~cm}^{3} \mathrm{coc}$ вила 45 и 103\%, а с использованием менее полярного элюента - смеси гексан:трихлорметан (7:3 по объему) при объеме элюента $2.5 \mathrm{~cm}^{3}-35$ и $86 \%$, соответственно. Низкая степень извлечения присадки «Максойл В» связана с его высокой молекулярной массой и, как следствие, необратимой сорбцией на сорбенте на основе немодифицированного силикагеля. Для более полного извлечения такого рода веществ, по-видимому, необходимо применение модифицированных сорбентов.

Сочетание сорбции из гексанового раствора вязкостных присадок на основе полиалкилметакрилата из базовой основы смазочных материалов и десорбции аналитов ацетоном показали большую эффективность гидроксилированного силикагеля по отношению к исследуемым аналитам.

Ключевые слова: вязкостные присадки, полиалкилметакрилат, смазочные масла, твердофазная экстракция, сорбция, десорбция, гель-проникающая хроматография, газовая хроматография.

\section{Введение}

В смазочные масла для повышения вязкости и улучшения вязкостно-температурных характеристик вносят специальные добавки - вязкостные присадки. В качестве добавок применяются полимеры и сополимеры - полиалкилметакрилаты, полиизобутилен, сополимеры олефинов (этилена, пропилена, бутилена), гидрированный полиизопрен, гидрированный сополимер стирола и бутадиена и др. [1-4], которые во многом определяют качество и ресурс моторного, гидравлического и других смазочных масел [5]. Это, в свою 
очередь, требует оценки состояния функциональных присадок в смазочных маслах, состоящих из базового масла и функциональных присадок.

Для определения вязкостных присадок в смазочных маслах требуется их предварительное извлечение [6-13]. Наиболее распространенными методами извлечения функциональных присадок из смазочного масла являются твердофазная (ТФЭ) [6-10] и жидкость-жидкостная экстракция (ЖЖЭ) [11-13]. Для извлечения полимерных присадок ЖЖЭ практически не применяется в силу их низкой растворимости в большинстве растворителей, используемых для ЖЖЭ [10], а также времени экстракции, стабильности и степени извлечения аналитов [9]. Связанные с извлечением присадок некоторые проблемы может устранить ТФЭ, которая позволяет работать с меньшим объемом анализируемой пробы и расходом элюента, ее эффективность определяется физико-химическими процессами между материалом сорбента и сорбатом. Возможность применения различных сорбентов для ТФЭ вязкостных присадок из смазочного материала определяется их сорбционными характеристиками «объем до проскока», объем удерживания, равновесный объем и степень извлечения, которые можно определить по выходной динамической кривой сорбции [14]. Для извлечения функциональных присадок из смазочного материала используют сорбент на основе немодифицированного силикагеля [6-7, 9-12], являющийся полярным, он прост в подготовке и обладает умеренной адсорбционной активностью по отношению к компонентам масел. С другой стороны, с увеличением молекулярной массы и полярности аналита адсорбция на данном сорбенте становится необратимой [15]. Присадки на основе полиалкилметакрилата, которые в настоящее время применяются для повышения вязкости и улучшения вязкостно-температурных характеристик, являются слабополярными высокомолекулярными веществами, поэтому для их извлечения из масляной основы наиболее применяемый сорбент на основе немодифицированного силикагеля для этих целей может оказаться неэффективным.

Цель данного исследования - изучение сорбционных материалов для твердофазного извлечения вязкостных присадок на основе полиалкилметакрилата из смазочного материала для последующего их хроматографического определения.

\section{Экспериментальная часть}

Объекты исследования - растворы индивидуальных товарных функциональных присадок на основе полиалкилметакрилата «Максойл В», полиметилметакрилат «Д» (ПМАД), предоставленные ПАО Средневолжским научно-следовательским институтом по нефтепереработке («СвНИИНП»).

Растворители, реагенты и стандартные образцы. Экспериментальные исследования проводили с использованием гексана, ос.ч., трихлорметана, ос.ч. и ацетона ос.ч. («Экос», Россия).

Оборудование. Хроматографическое определение компонентов товарных полимерных присадок осуществляли на хроматографе «LC 20 Prominence» (Shimadzu, Япония) с дегазатором DGU20A5, насосом LC20AD, автоматическим дозатором SIL-20A, термостатом колонок СТО-20АС и рефрактометрическим детектированием RID-20A по методике[10].

Идентификацию функциональных присадок в элюатах проводили на хроматографе GC-2010 (Shimadzu, Япония) с масс-спектрометрическим детектированием GCMS-QP2010 (Shimadzu, Япония) с использованием библиотеки масс-спектров NIST 07.

Сорбционные материалы и их характеристики. В качестве сорбционных материалов для твердофазного извлечения вязкостных присадок использовали концентрирующие патроны: «Диапак силикагель», размер частиц 63-200 мкм, диаметр пор $100 \mathrm{~A}^{0}$ (ЗАО «БиоХимМак СТ», 
Россия); гидроксилированный силикагель (Silica Gel 60), размер частиц 5-50 мкм («Merck», Германия).

Для определения сорбционных характеристик сорбентов полимерную присадку растворяли в гексане или смеси растворителей гексан : трихлорметан (7:3 по объему), пропускали через концентрирующие патроны со скоростью $1 \mathrm{~cm}^{3} /$ мин, отбирая соответствующие фракции в виалы. Анализ полученных фракций проводили методом гель-проникающей жидкостной хроматографии (ГПХ). Для этого элюаты выпаривали в токе азота с помощью генератора азота LCMS30-1 (Domnick Hunter, США), затем их перерастворяли в смеси растворителей гексан:трихлорметан (7:3 по объему). Элюаты перерастворяли в гексане для идентификации присадки в составе фракции. «Объемы до проскока» $\left(\mathrm{V}_{\mathrm{B}}\right)$, объем удерживания $\left(\mathrm{V}_{\mathrm{R}}\right)$ и равновесный объем $\left(\mathrm{V}_{\mathrm{E}}\right)$ определяли графически по динамическим кривым сорбции, число теоретических тарелок (ЧТТ) сорбентов (N) и динамическую емкость (ДЕ) рассчитывали по формулам [14]:

$$
\begin{array}{r}
\mathrm{N}=\frac{\mathrm{V}_{\mathrm{R}} \times\left(\mathrm{V}_{\mathrm{R}}-\sigma_{\mathrm{V}}\right)}{\sigma_{\mathrm{V}}^{2}} \\
Д E=\frac{V_{B} \times C}{m}
\end{array}
$$

где бv-стандартное отклонение на выходной динамической кривой сорбции; C - концентрация аналита, г/ $\mathrm{cm}^{3}$; $\mathrm{m}$ - масса сорбента, г.

Хроматографическое определение вязкостных присадок в элюатах. Функциональные присадки определяли методом ГПХ на жидкостном хроматографе с рефрактометрическим детектором по методике [10]. Условия анализа: колонка Phenogel (Phenomenex, США), диаметр частиц сорбента 5 мкм $(300 \times 7.8$ мм $)$, элюент - гексан : трихлорметан (70:30 по объему), скорость потока $1 \mathrm{~cm}^{3} /$ мин, температура термостата колонки и детектора $-30^{\circ} \mathrm{C}$.

Идентификацию функциональных присадок в элюатах проводили методом ГХ-МС с использованием встроенной библиотеки масс-спектров. Условия анализа: колонка HP-ULTRA 2 (Agilent Technologies, США), диаметр частиц 0.52 мкм (50 м $\times 0.320$ мм), начальная температура $100^{\circ} \mathrm{C}$, выдержка 2 мин, скорость нагрева $5^{\circ} \mathrm{C} /$ мин, конечная температура $290^{\circ} \mathrm{C}$, выдержка при конечной температуре 30 мин.

\section{Обсуждение результатов}

Для построения выходных динамических кривых сорбции необходимо было исключить преждевременное элюирование аналита с материала используемых сорбентов во время сорбции. Оптимизацию условий сорбции вязкостных присадок на основе полиалкилметакрилата проводили с учетом растворимости данных веществ в различных растворителях и смесях на их основе [10]. Кроме того, оптимальным вариантом с точки зрения простоты и эспрессности методики является прямой анализ элюата после ТФЭ методом ГПХ без стадии перерастворения в растворитель совместимый с материалом сорбента колонки, в данном случае элюентом является гексан : трихлорметан (7:3 по объему).

Сорбционные характеристики исследованных сорбентов. Для твердофазной экстракции функциональных присадок из смазочных материалов, как правило, используют концентрирующие патроны на основе силикагеля, обладающие низкой адсорбционной активностью по отношению к компонентам базовых масел и умеренной к большинству функциональных присадок [16]. Для сорбента «Диапак силикагель» были получены выходные динамические кривые сорбции вязкостных присадок на основе полиалкилметакрилата с использованием в качестве растворителей смеси гексан:трихлорметан (7:3 по объему) (рис. 1) и гексана (рис. 2). «Объемы до проскока» определили для присадок в растворителях с различной полярностью. В смеси гексан:трихлорметан (7:3 по объему) они составили 0.3 и $0.5 \mathrm{~cm}^{3}$, в гексане 0.6 и $0.8 \mathrm{~cm}^{3}$ для «Максойл В» и ПМАД соответственно (табл. 1). Для 


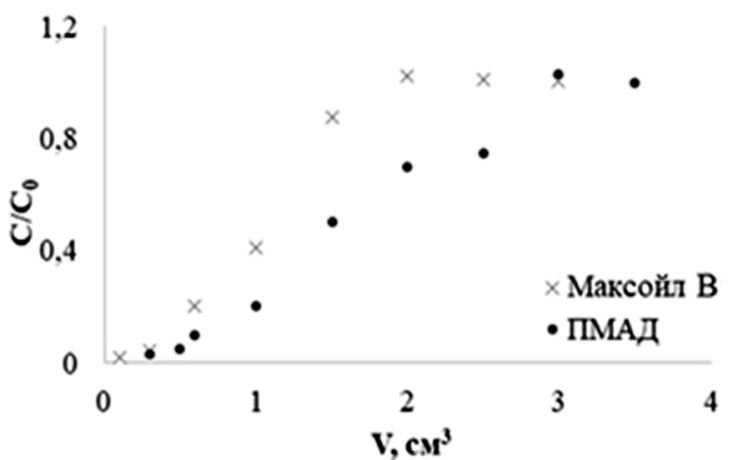

Рис. 1. Выходные динамические кривые сорбции вязкостных присадок на основе полиалкилметакрилата на концентрирую-

щем патроне «Диапак силикагель» с использованием в качестве растворителя смеси гексан:трихлорметан (7:3 по объему)

Fig. 1. Dynamic curves of sorption of viscous additives based on polyalkyl methacrylate on a concentrating cartridge "Diapak silica gel" using a mixture of hexane: trichloromethane ( $7: 3$ by volume) as a solvent

разных торговых присадок со схожим действующим веществом формы выходных динамических кривых сорбции были близки (рис. 1-2), что, по-видимому, обусловлено близостью физико-химических свойств компонентов и наличием общих функциональных групп. При использовании в качестве растворителя гексана рас-

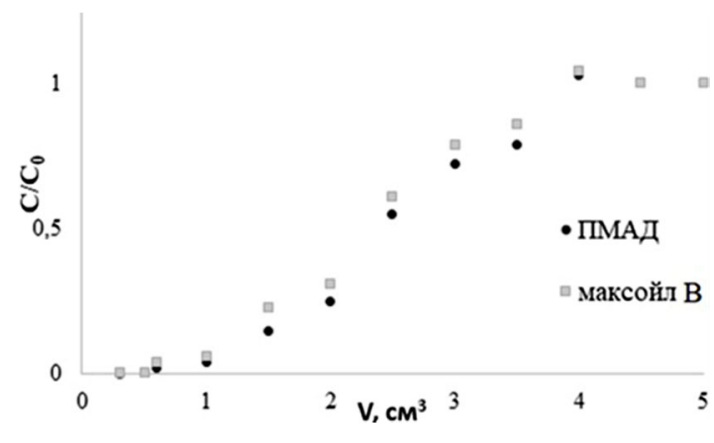

Рис. 2. Выходные динамические кривые сорбции вязкостных присадок на основе полиалкилметакрилата на концентрирующем патроне «Диапак силикагель» с использованием в качестве растворителя гексана

Fig. 2. Dynamic curves of sorption of viscous additives based on polyalkyl methacrylate on "Diapak silica gel" concentrating cartridge using hexane as a solvent

считанное ЧТТ сорбента больше, это обусловлено тем, что десорбция аклилметакрилатов - слабополярных молекул, с поверхности силикагеля неполярным растворителем затруднена.

Для сравнения сорбционных характеристик сорбентов с различным числом силанольных групп для твердофазной

Таблица 1. Основные сорбционные параметры сорбента «Диапак силикагель» по отношению к вязкостным присадкам на основе полиалкилметакрилата

Table 1. The main sorption parameters of "Diapak silica gel" sorbent in relation to viscous additives based on polyalkyl methacrylate ${ }^{*}$

\begin{tabular}{|c|c|c|c|c|c|c|c|c|c|}
\hline $\begin{array}{c}\text { Раство- } \\
\text { ритель }\end{array}$ & $\begin{array}{c}\text { при- } \\
\text { садка }\end{array}$ & $\begin{array}{c}\mathrm{V}_{\mathrm{R}}, \\
\mathrm{cm}^{3}\end{array}$ & $\begin{array}{c}\mathrm{V}_{\mathrm{B}}, \\
\mathrm{cm}^{3}\end{array}$ & $\begin{array}{c}\mathrm{V}_{\mathrm{E}}, \\
\mathrm{cm}^{3}\end{array}$ & $\mathrm{~S}_{\mathrm{r}}, \%$ & $\mathrm{~N}$ & $\begin{array}{c}\sigma_{\mathrm{v}}, \\
\mathrm{cm}^{3}\end{array}$ & $\begin{array}{c}\sigma_{\mathrm{v}}{ }^{\mathrm{R}}, \\
\mathrm{cm}^{3}\end{array}$ & $\begin{array}{c}\text { ДЕ г на 1 г } \\
\text { сорбента }\end{array}$ \\
\hline $\begin{array}{c}\text { смесь } \\
\text { гек- } \\
\text { сан:три- } \\
\text { хлорме- } \\
\text { тан (7:3 } \\
\text { по объ- } \\
\text { сой В }\end{array}$ & 1.1 & 0.3 & 1.83 & $\leq 8$ & $0.51 \pm 0.05$ & 0.8 & 0.43 & $0.016 \pm 0.003$ \\
\hline \multirow{2}{*}{ гексан } & ПМАД & 1.5 & 0.5 & 2.9 & $\leq 7$ & $0.90 \pm 0.06$ & 1 & 0.4 & $0.028 \pm 0.004$ \\
\cline { 2 - 10 } & Мак- & 2.2 & 0.83 & 3.93 & $\leq 7$ & $0.97 \pm 0.04$ & 1.37 & 1.73 & $0.046 \pm 0.006$ \\
\hline ПМАД & 2.19 & 1 & 3.94 & $\leq 8$ & $0.98 \pm 0.04$ & 1.19 & 1.75 & $0.055 \pm 0.006$ \\
\hline
\end{tabular}

* $\mathrm{V}_{\mathrm{R}}$ - объем удерживания; $\mathrm{V}_{\mathrm{B}}$ - «объем до проскока»; $\mathrm{V}_{\mathrm{E}}$ - равновесный объем; $\sigma_{\mathrm{V}}$ и $\sigma_{\mathrm{V}}{ }^{\mathrm{R}}$ - стандартные отклонения на выходной динамической кривой сорбции, $\mathrm{N}$ - число теоретических тарелок $* \mathrm{~V}_{\mathrm{R}}-$ retention volume; $\mathrm{V}_{\mathrm{B}}$ - "breakthrough volume"; $\mathrm{V}_{\mathrm{E}}$ - equilibrium volume; $\sigma_{\mathrm{V}}$ and $\sigma_{\mathrm{V}}{ }^{\mathrm{R}}-$ standard deviations on thedynamic sorption curve, $\mathrm{N}$ - number of theoretical plates 


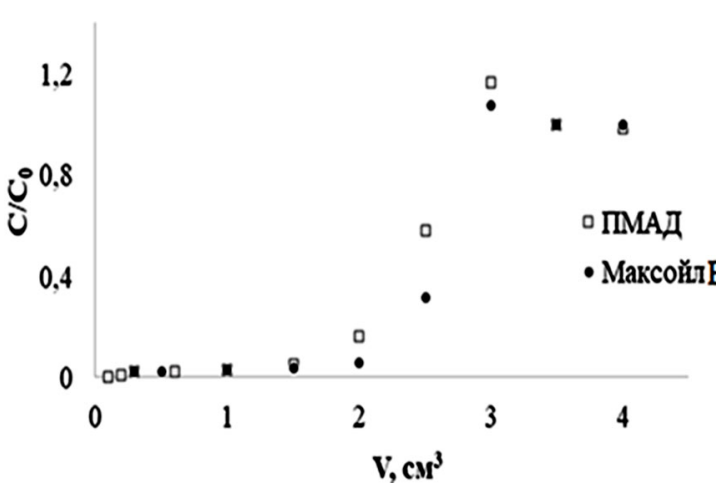

Рис. 3. Выходные динамические кривые сорбции вязкостных присадок на основе полиалкилметакрилата на гидроксилированном (0.5 г, зернение 5-50 мкм) с использованием в качестве растворителя смеси гексан:трихлорметан (7:3 по объему)

Fig. 3. Dynamic curves of sorption of viscous additives based on polyalkyl methacrylate on hydroxylated ( $0.5 \mathrm{~g}$, grain size 5-50 $\mu \mathrm{m})$ using a mixture of hexane:trichloromethane ( $7: 3$ by volume) as a solvent

экстракции вязкостных присадок из смазочных материалов, строили динамические кривые сорбции для гидроксилированного силикагеля с размером частиц 550 мкм. Для этого через патроны для ТФЭ, заполненные гидроксилированным силикагелем (0.5 г, зернение 5-50 мкм), с постоянной скоростью равной $1 \mathrm{~cm}^{3} /$ мин пропускали растворы полимерных присадок, в качестве растворителей использовали смесь гексан:трихлорметан (7:3 по объему) и гексан. Выходные динамические кривые сорбции для вязкостных присадок на основе полиалкилметакрилата на данном сорбенте обладали сигмоидальной формой (рис. 3-4), «объемы до проскока» для присадок «Максойл В» и ПМАД в смеси гексан:трихлорметан (7:3 по объему) составили 1.95 и $1.50 \mathrm{~cm}^{3}$, гексане -3.40 и $3.01 \mathrm{~cm}^{3}$ соответственно.

При сорбции полиалкилметакрилата на силикагелевом адсорбенте возможны электростатические взаимодействия сорбента с карбоксильной группой аналита, $\pi-\pi$ и межмолекулярные взаимодействия между структурой аналита и материалом сорбента. В силу слабополярного характера молекулы аналита его адсорбция из

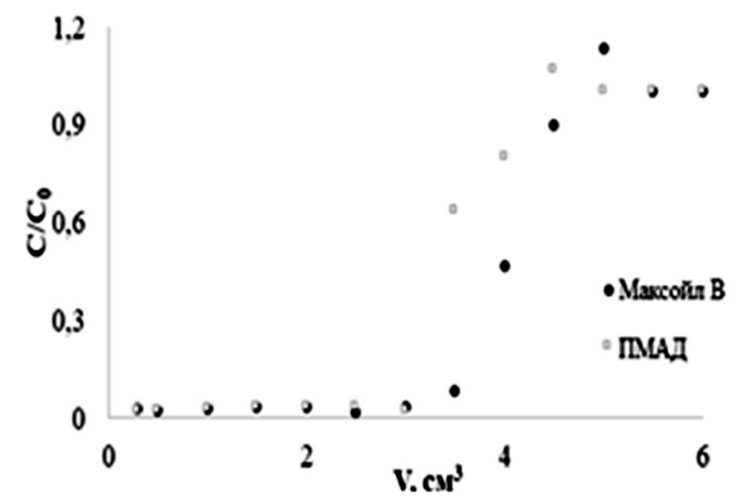

Рис. 4. Выходные динамические кривые сорбции вязкостных присадок на основе полиалкилметакрилата на гидроксилированном силикагеле $(0.5$ г, зернение 5-50 мкм) с использованием в качестве растворителя гексана

Fig. 4. Dynamic curves of sorption of viscous additives based on polyalkyl methacrylate on hydroxylated silica gel $(0.5 \mathrm{~g}$, grain

size 5-50 $\mu \mathrm{m}$ ) using hexane as a solvent

гексаного раствора протекает эффективнее, чем из более полярной смеси гексана и трихлорметана. Компоненты базового масла являются неполярными соединениями и слабо удерживаются гексаном на силикагелевом сорбенте [17]. Возможность выделения полимерных вязкостных присадок на основе полиалкилметакрилата из базовой основы смазочных материалов изучили в условиях различной полярности элюента. В табл. 1 и 2 приведены данные по основным сорбционным параметрам сорбента «Диапак силикагель» и гидроксилированного силикагеля по отношению к вязкостным присадкам на основе полиалкилметакрилата. Как видно, с увеличением дисперсности твердой фазы сорбента и количества силанольных групп растет адсорбция аналитов на силикагеле, что также согласуется с литературными данными [15]. Рассчи танные значения ЧТТ по отношению к товарным полимерным присадкам позволяют говорить о большей целесообразности применения гидроксилированного силикагеля (0.5 г, зернение 5-50 мкм) для сорбции данной группы соединений. Раз- 
Таблица 2. Основные сорбционные параметры гидроксилированного силикагеля $(0.5$ г, зернение 5-50 мкм) по отношению к вязкостным присадкам на основе полиалкилметакрилата* Table 2. The main sorption parameters of hydroxylated silica gel ( $0.5 \mathrm{~g}$, grain size 5-50 microns) in relation to viscous additives based on polyalkyl methacrylate*

\begin{tabular}{|c|c|c|c|c|c|c|c|c|c|}
\hline $\begin{array}{c}\text { Раство- } \\
\text { ритель }\end{array}$ & присадка & $\begin{array}{c}\mathrm{V}_{\mathrm{R}}, \\
\mathrm{cm}^{3}\end{array}$ & $\begin{array}{c}\mathrm{V}_{\mathrm{B}}, \\
\mathrm{cm}^{3}\end{array}$ & $\begin{array}{c}\mathrm{V}_{\mathrm{E}}, \\
\mathrm{cm}^{3}\end{array}$ & $\begin{array}{c}\mathrm{S}_{\mathrm{r}}, \\
\%\end{array}$ & $\mathrm{~N}$ & $\begin{array}{c}\sigma_{\mathrm{v}}, \\
\mathrm{cm}^{3}\end{array}$ & $\begin{array}{c}\sigma_{\mathrm{v}}{ }^{\mathrm{R}}, \\
\mathrm{cm}^{3}\end{array}$ & $\begin{array}{c}\text { ДЕ, } \\
\text { г на 1 г сор- } \\
\text { бента }\end{array}$ \\
\hline $\begin{array}{c}\text { Смесь } \\
\text { гек- } \\
\text { сан:три- } \\
\text { хлорме- } \\
\text { тан (7:3 } \\
\begin{array}{c}\text { по объ- } \\
\text { ему) }\end{array}\end{array}$ & $\begin{array}{c}\text { Максойл } \\
\text { В }\end{array}$ & 2.65 & 1.95 & 2.90 & $\leq 5$ & $13 \pm 3$ & 0.65 & 0.25 & $0.015 \pm 0.002$ \\
\hline \multirow{2}{*}{ гексан } & $\begin{array}{c}\text { Максойл } \\
\text { В }\end{array}$ & 4.10 & 3.4 & 4.70 & $\leq 3$ & $28 \pm 3$ & 0.7 & 0.6 & $0.333 \pm 0.005$ \\
\cline { 2 - 10 } & ПМАД & 3.30 & 3.01 & 4.30 & $\leq 4$ & $118 \pm 8$ & 0.29 & 1.1 & $0.295 \pm 0.006$ \\
\hline
\end{tabular}

ница в ЧТТ изученных сорбентов по отношению к полиалкилметакрилатам обусловлена, по-видимому, образованием водородных связей и электростатическими взаимодействиями между силанольными группами сорбента и аналитом. Разницу в эффективности гидроксилированных и негидроксилированных силикагелей по отношению к различным аналитам можно объяснить удалением при $100-120^{\circ} \mathrm{C}$ молекулярно-сорбированной воды с поверхности силикагеля в процессе гидроксилирования в нормальных условиях и ростом числа силанольных групп. Авторы [15] на основе ИКспектроскопических исследований также подтверждают разную эффективность различных типов силикагелей по отношению к аналитам.

Десорбция полимерных вязкостных присадок на основе полиалкиметакрилата. На немодифицированном силикагеле типа «Диапак силикагель» возможна необратимая адсорбция вязкостных присадок. Данные [15] показали, что адсорбция полярных и слабополярных молекул снижается с ростом количества силанольных групп сорбента, т.е. увеличивается степень извлечения аналита. Для изучения степени извлечения вязкостных присадок с гидроксилированного силикагеля (0.5 г, зернение 5-50 мкм) гексановый раствор функциональной присадки наносили на патрон для ТФЭ и проводили элюирование различными объемами элюента от 0.1 до $3 \mathrm{~cm}^{3}$ с шагом $0.3 \mathrm{~cm}^{3}$. Элюаты затем выпаривали в токе азота, перерастворяли в смеси растворителей гексан:трихлорметан (7:3 по объему) и анализировали по методике ГПХ [10]. ГХ-МС идентификацию полимерной присадки в составе элюатов проводили с использованием библиотеки масс-спектров NIST 07 (рис. 5). По полученным данным строили кривые десорбции товарных полимерных присадок с гидроксилированного силикагеля. Анализ кривых десорбции товарных вязкостных присадок с гидроксилированного силикагеля с использованием смеси гексан:трихлорметан (7:3 по объему) (рис. 6) и ацетона (рис. 7) показал, что наибольшей элюирующей силой обладает ацетон. Степень извлечения товарных вязкостных присадок «Максойл В» и ПМАД при оптимальном объеме элюента - ацетона, $1.5 \mathrm{~cm}^{3}$ составила 45 и $103 \%$ соответственно. Отличная от $100 \%$ степень извлечения присадки ПМАД может быть связана с возможным на нее влиянием анализируемой матрицы или погрешностью методики определения. При использовании менее полярного элюента смеси гексан : трихлорметан (7:3 по объему), данная величина при объеме элюента $2.5 \mathrm{~cm}^{3}$ составила 35 и 86\%. Низкая степень извлечения присадки «Максойл В» 


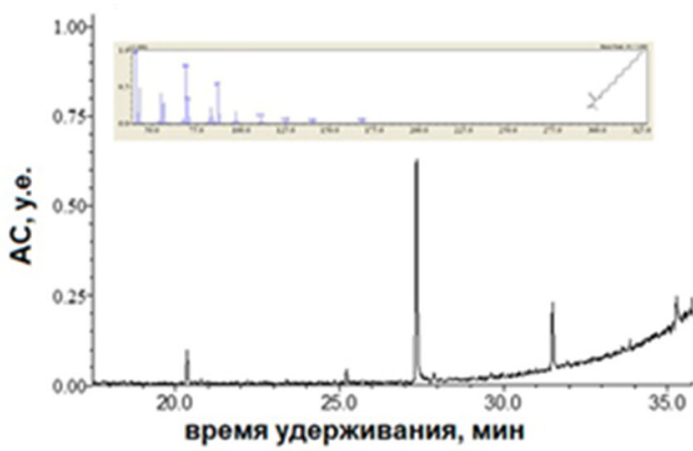

Рис. 5 Хроматограмма элюата товарной вязкостной присадки на основе полиалкилметакрилата

Fig. 5. Chromatogram of the eluate of a commercial viscous additive based on polyalkyl methacrylate

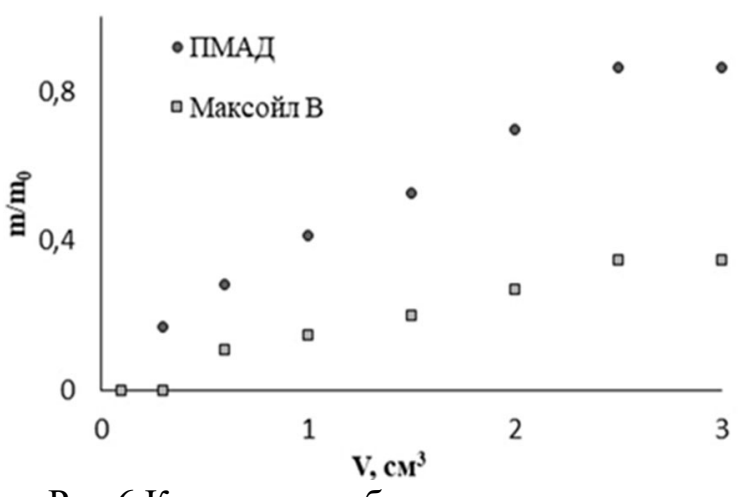

Рис.6 Кривая десорбции вязкостных полимерных присадок на основе полиалкилметакрилата с гидроксилированного силикагеля смесью гексан:трихлорметан (7:3 по объему)

Fig. 6. Curve of desorption of viscous polymer additives based on polyalkyl methacrylate from hydroxylated silica gel with a hexane:trichloromethane mixture ( $7: 3$ by volume)

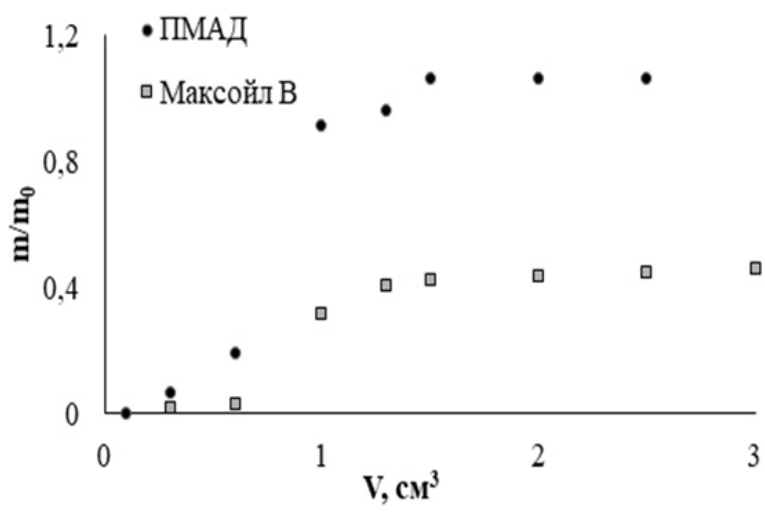

Рис. 7. Кривая десорбции вязкостных присадок на основе полиалкилметакрилата с гидроксилированного силикагеля ацетоном

Fig. 7. Curve of desorption of viscous additives based on polyalkyl methacrylate from hydroxylated silica gel with acetone

связана с его высокой молекулярной массой и, как следствие, необратимой сорбцией на сорбенте на основе немодифицированного силикагеля. Для более полного извлечения такого рода веществ, по-видимому, необходимо применение модифицированных сорбентов, например, силикагеля модифицированного оксидами металлов или сорбенты на полимерной основе.

\section{Заключение}

Оценена эффективность применения различных типов сорбционных материа- лов - концентрирующих патронов на немодифицированном силикагеле «Диапак силикагель» и гидроксилированного силикагеля, для извлечения вязкостных присадок на основе полиалкилметакрилата из базовой основы смазочных материалов. Изучены основные сорбционные характеристики обоих типов сорбентов по отношению к товарным вязкостным присадкам, растворенным в растворителях с разной полярностью, рассчитаны числа теоретических тарелок по отношению к товарным полимерным присадкам «Максойл В» и ПМАД. 
Сочетание сорбции из гексанового раствора вязкостных присадок на основе полиалкилметакрилата из базовой основы смазочных материалов и десорбции аналитов ацетоном показали большую эффективность гидроксилированного силикагеля по отношению к исследуемым аналитам. Последующую ГХ-МС идентификацию и определение выделенной полимерной присадки в составе элюатов проводили с использованием библиотеки масс-спектров NIST 07.

Исследования проводились в рамках выполнения гранта РФФИ (№19-33-90175) с использованием научного оборудования ЦКП «Эколого-аналитический иентр» Кубанского госуниверситета

\section{Список литературы}

1. Pranab G., Moumita D. // Journal of Petroleum Science and Engineering. 2014. Vol. 119. pp. 79-84.

2. Bapat A.P., Erck R., Seymour B. T., Zhao B. et al. // European Polymer Journal. 2018. Vol. 108. pp. 38-47.

3. Казанцев О. А., Самодурова С.И, Каморин Д.М, Сивохин А.П. и др. // Нефтехимия. 2014. Т. 54. № 6. С. 485-488.

4. Pranav Dev Srivyasa, Charoob M.S. // Materials Today: Proceedings. 2019. Vol. 18. part 7. pp.4773-4781.

5. Кулиев А.М. Химия и технология присадок к маслам и топливам. 2-е изд перераб. Л. Химия. 1985. $312 \mathrm{c.}$

6. Ахмедов Р.Л., Кравцова С.С., Дычко, К.А., Рамусь И.В. // Аналитика и контроль. 2019. T. 23. № 4. С. 532-538.

7. Приваленко А.Н., Красная Л.В., Чернышева А.В., Зуева В.Д. и др. // Нефтепереработка и нефтехимия. 2018. № 7. С. 23-26.

8. Проскурина Н.А., Ильин М.М., Даванков В.А., Сычёв К.С. и др. // Журнал физической химии. 2007. Т. 81. № 3. С. 502-506.

9. Темердашев 3.А., Иванова Ю.А., Колычев И.А., Аверина Е.С. и др. // Журнал аналитической химии. 2019. Т.74. №12. С. 922- 929.
10. Иванова Ю.А., Темердашев 3.А., Колычев И.А., Киселева Н.В. // Аналитика и контроль. 2021. Т. 25. № 1. С. 53-62.

11. Зайцев С.В., Кишневский В.А., Шуляк И.Д. // Восточно-европейский журнал передовых технологий. 2015. Т. 2. № 6. С. 21-28.

12. Y. Xiang, X. Qian, M. Hua, B. Cheng et al. // Analytical Letters. Electrochemistry. 2016. Vol. 49. No 10. pp. 1526-1536.

13. Рудаков О.Б, Фан Винь Тхинь // Сорбционные и хроматографические проиессы. 2008. T.8. № 1. C. 141-146.

14. Bielicka-Daszkiewicz K. // Talanta. 2009. Vol. 80. pp. 614-621

15.Чукин Г.Д. Химия поверхности и строение дисперсного кремнезёма. М. Типография Паладин. 2008. 172 с.

16. Rudnick R. Synthetics, Mineral Oils, and Bio-Based Lubricants. Chemistry and Technology. Taylor and Francis group. 2020. 1194 p.

17. Тагиров Т.К. Методика определения присадок в смазочных материалах методом тонкослойной хроматографии. М. Рос. Федер. центр судебн. экспертизы. 2007. 27 с.

\title{
Sorption materials for the solid-phase extraction of viscous additives based on polyalkyl methacrylate from lubricants
}

\author{
(C) 2021 Ivanova Yu.A., Temerdashev Z.A., Kiseleva N.V., Makhotkina D.A. \\ Kuban State University, Krasnodar
}

The study was devoted to the investigation of the sorption materials for the solid-phase extraction of viscous additives based on polyalkyl methacrylate from a lubricant and chromatographic determination of the selected additives. The objects of study were individual commercial functional additives based on polyalkyl 
methacrylate "Maksoil V", polymethyl methacrylate "D" (PMAD). Concentrating cartridges based on unmodified silica gel "Diapak Silica gel" and hydroxylated silica gel (grain size 5-50 microns) were used as sorption materials. The concentration of functional additives was determined by gel permeation chromatography (GPC). GC-MS identification of polymer additives in eluates was performed using the NIST 07 mass spectra library. For each sorbent, dynamic sorption curves were plotted, sorption characteristics were calculated in relation to the investigated viscous additives ("breakthrough volume", equilibrium volume, retention volume, etc.). "Breakthrough volumes" using both sorbents were determined for the investigated additives in solvents with different polarities. For the "Diapak Silica gel" sorbent, the "breakthrough volumes" for the "Maxoil B" and PMAD additives were: in a hexane:trichloromethane mixture ( $7: 3$ by volume) 0.3 and $0.5 \mathrm{~cm}^{3}$ and in hexane 0.6 and $0.8 \mathrm{~cm}^{3}$, respectively. When the solid-phase extraction of commercial viscosity additives "Maxoil B" and PMAD with hydroxylated silica gel was carried out, the "breakthrough volumes" were: in a mixture of hexane: trichloromethane (7:3 by volume) 1.95 and $1.50 \mathrm{~cm}^{3}$ and in hexane 3.40 and $3.01 \mathrm{~cm}^{3}$, respectively. The degree of extraction of commercial viscous additives "Maxoil B" and PMAD by hydroxylated silica gel with the optimal volume of eluent (acetone) of $1.5 \mathrm{~cm}^{3}$ was 45 and $103 \%$, and using a less polar eluent - a mixture of hexane:trichloromethane ( $7: 3$ by volume) with an eluent volume of $2.5 \mathrm{~cm}^{3}$ was 35 and $86 \%$, respectively. The low degree of extraction of the "Maxoil B" additive is associated with its high molecular weight and, as a consequence, irreversible sorption on a sorbent based on unmodified silica gel. For a more complete extraction of these types of substances it is probably necessary to use modified sorbents.

The combination of sorption of viscous additives based on polyalkyl methacrylate from the base of lubricants from a hexane solution and desorption of analytes with acetone showed a higher efficiency of hydroxylated silica gel in relation to the studied analytes.

Keywords: viscous additives, polyalkyl methacrylate, lubricating oils, solid phase extraction, sorption, desorption, gel permeation chromatography, gas chromatography.

\section{References}

1. Pranab G., Moumita D. Journal of Petroleum Science and Engineering, 2014, Vol. 119, pp. 79-84. doi: 10.1080/10916460701700864

2. Bapat A.P., Erck R., Seymour B.T., Zhao B. et al., European Polymer Journal, 2018, Vol.108, pp. 38-47. doi: 10.1016/j.eurpolymj. 2018.08.026

3 Kazantsev O.A., Samodurova S.I., Kamorin D.M., Sivokhin A.P. et al., Petroleum chemistry, 2014, Vol. 54, No 6, pp. 473-476. doi:10.1134/S0965544114060073

4. Pranav Dev Srivyasa, Charoob M.S. Materials Today: Proceedings, 2019, Vol. 18, part 7, pp.4773-4781. doi.org/10.1016/j.matpr.2019.07. 465

5. Kuliev A.M. Khimiya i tekhnologiya prisadok k maslam i toplivam. 2-e izd pererab, L., Khimia,1985, 312 p.

6. Akhmedov R.L., Kravtsova S.S., Dychko, K.A., Ramus' I.V., Analytics and control, 2019, Vol. 23, No. 4, pp. 532-538. doi: 10.15826/analitika.2019.23.4.001

7. Privalenko A.N., Krasnaya L.V., Chernysheva A.V., Zueva V.D. et al., Neftekhimiya $i$ neftepererabotka, 2017, No 7, pp. 23-26.

8. Proskurina N.A., Il'in M.M., Davankov V.A., Sychev K.S. et al., Russian Journal of Physical Chemistry A, 2007, Vol. 81, No 3, pp. 424-427.
9. Temerdashev Z.A., Ivanova Yu.A., Kolychev I.A., Averina E.S. et al., J. of Analytical Chemistry, 2019, Vol. 74, No 12, pp. 1202-1208. doi: 10.1134/S0044450219120132

10. Ivanova Yu.A., Temerdashev Z.A., Kolychev I.A., Kiseleva N.V., Analytics and control, 2021, Vol. 25, No 1, pp. 53-62. doi: 10.15826/ analitika.2021.25.1.003

11. Zaitsev S.V., Kishnevskii V.A., Shulyak I.D., Vostochno-evropeiskii zhurnal peredovykh tekhnologii, 2015, Vol. 2, No 6, pp. 21-28. doi: 10.15587/1729-4061.2015.40896

12. Xiang Y., Qian X., Hua M., Cheng B. et al., Analytical Letters. Electrochemistry, 2016, Vol. 49, No 10, pp. 1526-1536. doi.org/10.1080 /00032719.2015.1118484

13. Rudakov O.B, Fan Vin' Tkhin', Sorbtsionnye i khromatograficheskie protsessy, 2008, Vol. 8, No 1, pp. 141-146.

14. Bielicka-Daszkiewicz K., Talanta, 2009, Vol. 80, pp. 614-621. doi: 10.1016/j.talanta.2009.07.037

15. Chukin G.D. Khimiya poverkhnosti $i$ stroenie dispersnogo kremnezema. M., Paladin Printing House, Printa LLC, 2008, 172 p.

16. Rudnick R. Synthetics, Mineral Oils, and Bio-Based Lubricants. Chemistry and Technology. Taylor and Francis group, 2020, 1194 p.

17. Tagirov T.K. Metodika opredeleniya prisadok v smazochnykh materialakh metodom tonkosloinoi khromatografii. M., Ros. Feder. forensic center expertise, 2007, $27 \mathrm{p}$. 
Темердашев Зауаль Ахлоович - д.х.н., профессор, зав. кафедрой аналитической химии факультета химии и высоких технологий, Кубанский государственный университет, Краснодар

Киселева Наталия Владимировна - к.Х.н., доцент кафедры аналитической химии факультета химии и высоких технологий, Кубанский государственный университет, Краснодар

Иванова Юлия Анатольевна - аспирант кафедры аналитической химии факультета химии и высоких технологий, Кубанский государственный университет, Краснодар

Махоткина Дарья Александровна - студент кафедры аналитической химии факультета химии и высоких технологий, Кубанский государственный университет, Краснодар
Temerdashev Zaual A. - doctor of chemical sciences, professor and the Head Department of Analytical Chemistry, Faculty of Chemistry and High Technologies, Kuban State University, Krasnodar. e-mail: temza@kubsu.ru

Kiseleva Natalia V. - Ph.D. in Chemistry, Associate Professor Department of Analytical Chemistry, Faculty of Chemistry and High Technologies, Kuban State University, Krasnodar. e-mail: lab284b@mail.ru

Ivanova Yuliya A. - Ph. D. student of the Department of Analytical Chemistry, Faculty of Chemistry and High Technologies, Kuban State University, Krasnodar. e-mail: uyliu@mail.ru

Makhotkina Dar'ya A. - student of the Department of Analytical Chemistry, Faculty of Chemistry and High Technologies, Kuban State University, Krasnodar. e-mail: daria_ma23@mail.ru 